\title{
Understanding Pregnant Women with Opioid Use Disorder
}

\author{
Deborah Stiffler, Mia Amundson, Lauren Hapke, \\ Emilie Harvey, Samantha Sizemore, Savannah Smith
}

Indiana University School of Nursing, Indianapolis, IN, USA

\begin{abstract}
Background: Pregnant women with opioid use disorder are a major concern to the healthcare industry. They are not only one of the most stigmatized groups but are in need of outreach. Women who are afflicted by opioid addiction are a highly vulnerable group who are at risk of adverse pregnancy outcomes and perinatal complications. The purpose of this study was to do a metasynthesis of the literature to gain a better understanding of the women's perspective who are addicted to opioid during pregnancy.

Subjects and Method: We conducted an exhaustive literature search for qualitative studies that focused on women with opioid used disorder during pregnancy and postpartum. After conducting a rigorous methodological protocol for meta-synthesis described by Joanna Briggs Institute, ten studies met the criteria for inclusion into this study. We used the Qualitative Assessment and Review Instrument (QARI) from the Joanna Briggs Institute to assist with data management. We extracted the representative quotations and categorized them into like themes.

Results: There were three themes formulated from this meta-synthesis: overarching fear, trust and educational deficits. This meta-synthesis of qualitative studies leads to greater understanding of how pregnant women with opioid use disorder perceive the consequences of their actions.

Conclusion: Implications from this meta-synthesis will inform those working with opioid addicted pregnant women and aid in establishing best practices for them and their infants by revealing their addiction experiences and narratives.
\end{abstract}

Keywords: opioid use disorder, pregnancy, stigma

\section{Correspondence:}

Deborah Stiffler. Indiana University School of Nursing, Indianapolis, IN, USA. Email: dstiffle@iu.edu.

\section{BACKGROUND}

Opioid use disorder (OUD) is a problematic pattern of opioid use that causes significant impairment or distress (Center for Disease Control and Prevention [CDC], 2017). In the United States, the opioid addiction has increased to the point of being a public health crisis (Kaiser Family Foundation [KFF], 2018). Addiction is no longer in the back streets with substances such as heroin, but now anyone who has the ability to obtain prescription opioids such as oxyco- done and hydrocodone has the potential of becoming addicted. As many as 1.7 million people have an addiction to prescription opioids as compared to 626,000 heroinaddicted individuals (KFF, 2018). In some areas, up to $40 \%$ of Medicaid, non-elderly patients are addicted to opiates (KFF, 2018). Deaths from opioid overdoses are highest among white, non-Hispanic males. Black, non-Hispanic males have the second highest death rate from opioid overdose. Hispanic men have the lowest rate. Even though men have the highest rate of deaths from opiate overdose, the rate of opioid use is growing in women, and in 2016, the female death rate was 8.5 deaths per 100,000 women (KFF, 2018).

Many abusers/addicts become depen- 
dent after having a prescription for pain medication for an injury or surgery. The medication creates artificial neurotransmitters that act on the dopamine and endorphin sensors in the brain causing pleasure and euphoria. After continued use of the medication, the body can no longer produce these sensations on its own, and the medication is needed in larger quan- tities to cause the euphoria previously felt (National Institute on Drug Abuse [NIDA], 2014). Hallmarks of the disorder are decreased sensitivity to use, being pre- occupied with wanting to use the drug, feeling helpless to control these feelings, and ambivalence to the negative conse- quences of the drug use (NIDA, 2014).

Treatment for this addictive disorder can be difficult because there are many factors that motivate drug use. Abstinence only programs of rehabilitation have the highest rate of relapse (McHugh et al., 2010). Combined therapy programs with support groups and behavioral therapy have the best results in treating addictive disorders (McHugh et. al, 2010). However, the elements impacting addicts is the chro- nic lack of accessible, quality treatment.

Just as opioid use has dramatically increased in the general population, the rate of women becoming addicted has increased to nearly one third of those seeking addiction care (Nordenfors and Höjer, 2017). Women are considered the primary childcare provider from the moment they become pregnant through the early developmental years, hence, women who are addicted, especially if pregnant, are looked upon as more deviant and vilified to a greater extent than men (Nordenfors and Höjer, 2017; Watson and Parke, 2011). Pregnant women are turning to opioid use at a steadily growing rate, and women who are addicted are becoming pregnant (CDC, 2017). Neonatal abstinence syndrome (NAS) is a group of conditions that are caused when a baby has been exposed to drugs during pregnancy. NAS has increased from 1.5 cases per 1,000 hospital births in 1999 to 6.0 per 1,000 hospital births in 2013 (NIDA, 2015). States with increased NAS prevalence have high rates of opioid prescriptions. Treating NAS infants costs hospitals approximately 1.5 billion a year more than treating non-NAS infants; the majority of these charges $(81 \%)$ are paid by state Medicaid programs (NIDA, 2015). For women diagnosed with opioid use disorder, it is challenging to manage the many aspects of their lives coupled with demands and pressure to adhere to healthy pregnancy practices (NIDA, 2015).

Healthcare of pregnant women with OUD is difficult and best practices are important. The provider of care may not understand why any mother would self- administer opioids, and the provider may exhibit unconscious bias toward the mother. This article sought out research from the patient perspective with a plan to inform healthcare providers about opioid addicted pregnant women and their infants by revealing the woman's addiction experiences and narratives. Much research has focused on physiologic effects of maternal opioid use on fetal outcomes without taking into account the woman's experience (Ross, 2015). Documenting the mother's percept- ions or motivations is limited in scope and difficult to find.

\footnotetext{
SUBJECTS AND METHOD

1. Study design

This systematic search strategy included qualitative studies that addressed the woman's perspective of living with opioid use disorder while pregnant or early postpartum. Only qualitative studies with a patient perspective on the self-perceived
} 
consequences or experiences of opioid use on pregnancy or early postpartum, including methods related to phenomenology, focus groups, action research, grounded theory, or ethnography were included. Quantitative outcome measures were not included.

We obtained articles through a systematic literature search of online databases. The databases included were PubMed (2007-2017), PsychInfo (2000-2017), CINAHL (2007-2017), EBSCO (1996-2017), and Ovid (2007-Current). The period reflects the previous 10 years, which is a period of rapid increase of opioid use. The search terms used included: "pregnancy", "opioid addiction", "perception", "addiction" and "opioid addicted mothers" to seek out appropriate articles. The search terms were widely applied in order to obtain a robust result for qualitative articles. Inclusion criteria: the study must be printed in English; be a research study using a qualitative method; and be relevant to a woman's perception or experiences of using opioid drugs in a way other than prescribed while pregnant or early post-partum. The authors found 303 articles through searching the databases. They reviewed the titles and abstracts of each study as a first pass to determine if the study met the criteria. The authors obtained and evaluated twenty full text articles and excluded 13. We excluded two of the articles because they were quantitative rather than qualitative and the remaining were excluded because they did not focus on the women's perceptions, but instead on fetal heart rate, addiction help, metabolic effects of addiction, or legal considerations. We performed a backward search of the references by hand and found seventeen potential articles. Out of these, we added three additional articles (Figure 1).

\section{Data extraction}

After a final review, ten articles matched the inclusion criteria for this review (See Table 1). The authors reviewed and critically evaluated each of the ten included qualitative articles by answering a series of standard evaluation questions developed by the Joanna Briggs Institute. The authors compared appraisals, and the authors reached congruence before entering the data into the Qualitative Assessment and Review Instrument (QARI), an online assessment tool provided by the Joanna Briggs Institute. We used this assessment to evaluate each study and determine its credibility, quality, and whether it should be ultimately included. Once the authors determined inclusion, they used the QARI instrument to assist in determining the findings, developing themes, and produce synthesized findings. In order to justify credibility, the authors confirmed that the data supported the developed themes.

RESULTS
The authors identified sixteen findings and
categorized them into seven themes. The
seven themes were meta-synthesized into
three synthesized findings. The three syn-
thesized findings were Overarching Fear,
Trust, and Educational Deficits.

\section{Overarching Fear}

The synthesized finding of Overarching Fear included three themes: Fear of Repercussion, Internal Ambivalence, and Stigma (See Figure 2).

Fear of repercussion. The women who were addicted to opioids feared authority figures that kept many women from seeking treatment. If they were in prenatal care or when they went into the hospital for delivery, they felt powerless regarding their care. Women feared that if they gave birth or sought out help in a hospital setting, authorities would take their child away. 
Explicit decisions

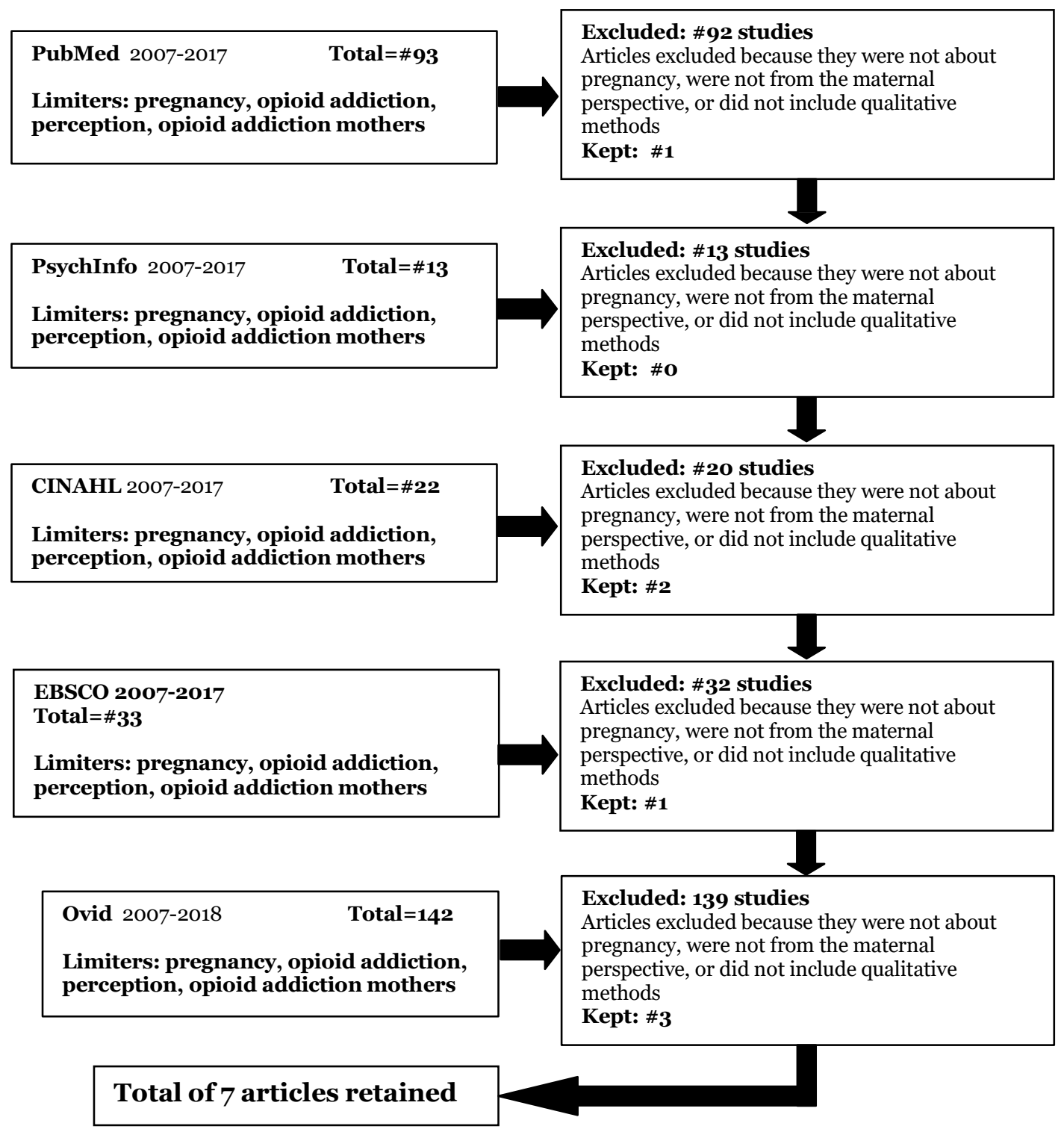

Figure 1. Article Decisions

Providers sent many women to treatment centers, and the women did not have any options about the treatments. One woman stated, "I was given no option. If you withdraw you die...stay on methadone or we're going to call CPS on you" (Howard, 2016). Fear of child protective services (CPS) was very real for addicted women. They felt like they were being watched, and if they stepped out of line, CPS would detox at home by myself so I would't have to have a baby born that has withdrawals (Howard, 2016). An- other woman found that she was "kidnap" they baby after delivery.

Internal ambivalence. Women who were addicted to opioids can have many ambivalent feelings. They may be ambivalent towards their pregnancy and wonder if they should continue the pregnancy. Many woman did not have the monetary means to choose an abortion. If they kept the pregnancy, there was ambivalence between continuing the addiction and concern for how the opioids would affect the pregnancy. 
"I didn" $t$ know what to do. I felt I couldn" $t$ stop taking drugs, how could I be a good mother? Afterwards, I could see things more clearly: I could stop it for this child.
My baby would save me and it gave me strength enough to carry on (Silva et al., 2012)."

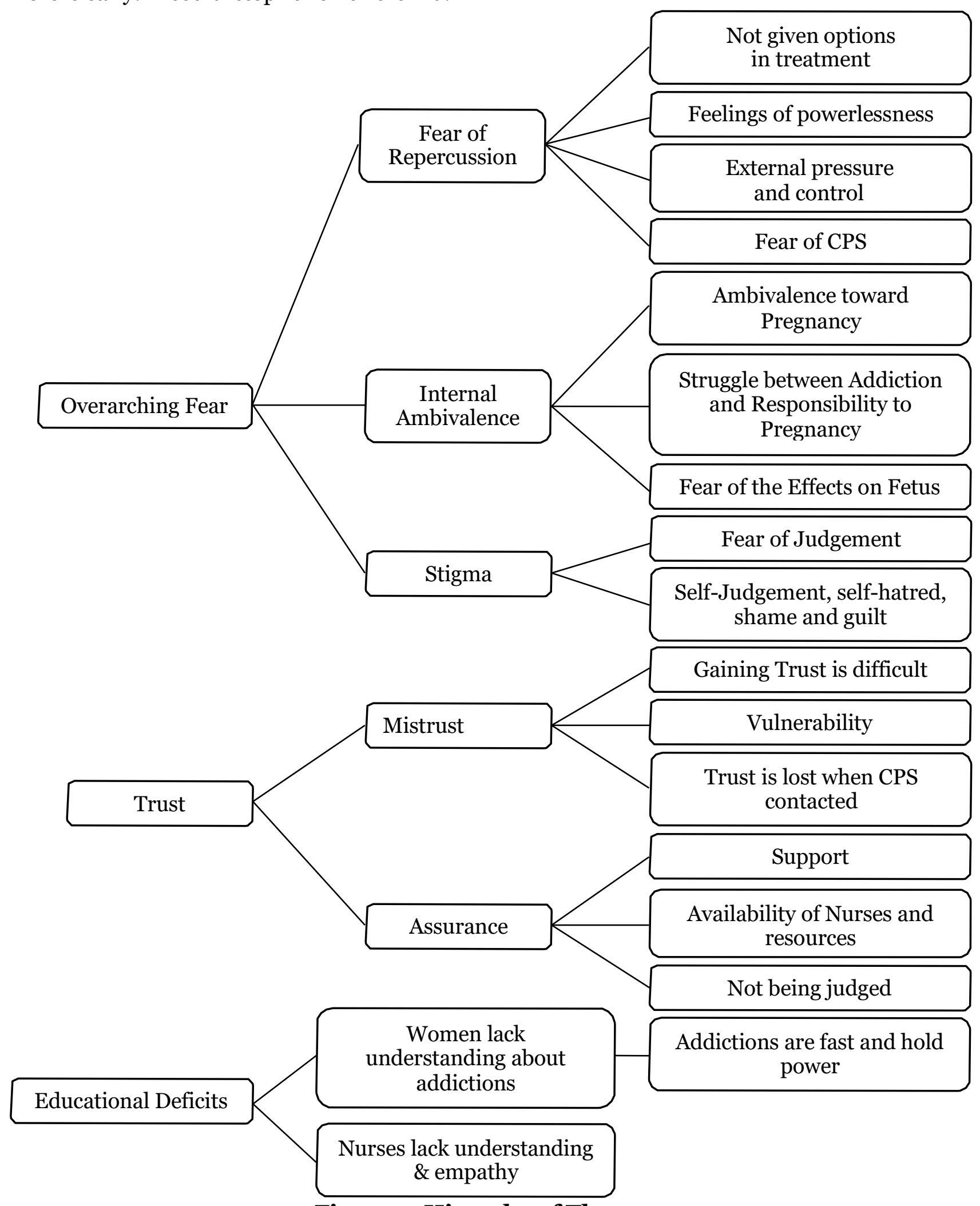

Figure 2. Hierachy of Themes 
Journal of Maternal and Child Health (2019), 4(6): 461-473

https://doi.org/10.26911/thejmch.2019.04.06.07

Table 1. Articles used in review

\begin{tabular}{|c|c|c|c|c|c|}
\hline Title & Authors & Participants & Method & Data collection & Findings \\
\hline $\begin{array}{l}\text { Substance, structure and stigma: } \\
\text { Parents in the UK accounting for opioid } \\
\text { substitution therapy during the ante- } \\
\text { natal and Postnatal periods (2013) }\end{array}$ & $\begin{array}{l}\text { Chandler A, Whittaker } \\
\text { A, Cunningham-Burley } \\
\text { S, Williams N, Mc- } \\
\text { Gorm K, Mathews G }\end{array}$ & $\begin{array}{l}\text { Purposive sample of } 19 \\
\text { opioid dependent } \\
\text { service workers (15 } \\
\text { women, } 4 \text { men) }\end{array}$ & $\begin{array}{l}\text { Analyzed thema- } \\
\text { tically using cons- } \\
\text { tant comparison }\end{array}$ & $\begin{array}{l}\text { Longitudinal data } \\
\text { was collected by } 3 \\
\text { semi-structured } \\
\text { interviews }\end{array}$ & $\begin{array}{l}\text { Participants were currently in an opioid substitution therapy } \\
\text { (OST) program. Themes included: OST as a facilitator of normal } \\
\text { parenthood; OST as a barrier to normal family life }\end{array}$ \\
\hline $\begin{array}{l}\text { Experiences of Mothers of } \\
\text { Infants with NAS in the } \\
\text { NICU (2014) }\end{array}$ & $\begin{array}{l}\text { Cleveland LM, Bonugli } \\
\mathrm{R}\end{array}$ & $\begin{array}{l}15 \text { Hispanics Sub- } \\
\text { stance addicted } \\
\text { mothers of infants with } \\
\text { NAS }\end{array}$ & $\begin{array}{l}\text { Qualitative } \\
\text { Content analysis }\end{array}$ & $\begin{array}{l}\text { Semi-structured } \\
\text { individual inter- } \\
\text { views }\end{array}$ & $\begin{array}{l}4 \text { themes: understanding addiction; watching the infant } \\
\text { withdraw; judging; trusting the nurses }\end{array}$ \\
\hline $\begin{array}{l}\text { "Try not to judge." Mothers of substance } \\
\text { of exposed infants (2013) }\end{array}$ & Cleveland LM, Gill SL & $\begin{array}{l}5 \text { women on metha- } \\
\text { done between the age } \\
\text { of } 22-37\end{array}$ & $\begin{array}{l}\text { Qualitative content } \\
\text { analysis }\end{array}$ & $\begin{array}{l}\text { Semi-structured } \\
\text { interviews }\end{array}$ & $\begin{array}{l}4 \text { themes: "try not to judge," "scoring" the baby, "share with me," } \\
\text { and "I'm the mother here! }\end{array}$ \\
\hline $\begin{array}{l}\text { Mothers' experience of methamphetamine } \\
\text { addiction: A case-based analysis of } \\
\text { rural, Midwestern women (2009) }\end{array}$ & $\begin{array}{l}\text { Haight WL, } \\
\text { Carter- } \\
\text { Black JD, Sheridan K }\end{array}$ & $\begin{array}{l}4 \text { rural, white, single } \\
\text { women in their } 30 \mathrm{~s} \text {, in } \\
\text { recovery from } \\
\text { methamphetamine } \\
\text { addiction }\end{array}$ & $\begin{array}{l}\text { Description of } \\
\text { cases Constructed } \\
\text { through Multiple } \\
\text { readings of } \\
\text { Transcripts }\end{array}$ & $\begin{array}{l}\text { Face to face, semi- } \\
\text { structured inter- } \\
\text { views }\end{array}$ & $\begin{array}{l}\text { "When you get sober, you get a heart again;" "This is a whole } \\
\text { different world;" "drugs were more powerful than the love for my } \\
\text { kids;" "You still had responsibilities...until you don't see the point } \\
\text { in it anymore;" }\end{array}$ \\
\hline $\begin{array}{l}\text { Experience of opioid-dependent women } \\
\text { in their prenatal and postpartum care: } \\
\text { implications for social workers in health } \\
\text { care (2016) }\end{array}$ & Howard $\mathrm{H}$ & $\begin{array}{l}30 \text { English speaking } \\
\text { women } \\
\text { within } 6 \text { months of } \\
\text { delivery }\end{array}$ & $\begin{array}{l}\text { Interpretive } \\
\text { phenomenology }\end{array}$ & $\begin{array}{l}\text { Group interviews } \\
\text { of postpartum } \\
\text { women }\end{array}$ & $\begin{array}{l}\text { Decision making about treatment choices during pregnancy; } \\
\text { Reflections on treatment decisions by health care providers; fear } \\
\text { of separation from their infants; feeling under surveillance }\end{array}$ \\
\hline $\begin{array}{l}\text { Mothers with substance } \\
\text { and alcohol abuse-- } \\
\text { support through pregnancy } \\
\text { and early infancy (2017) }\end{array}$ & Nordenfors M, Höjer I & $\begin{array}{l}17 \text { women between the } \\
\text { ages of } 21-40 \text {, }\end{array}$ & $\begin{array}{l}\text { Qualitative } \\
\text { Content } \\
\text { analysis }\end{array}$ & $\begin{array}{l}\text { Individual semi- } \\
\text { Structured inter- } \\
\text { views }\end{array}$ & $\begin{array}{l}\text { Themes: initial ambivalence to the pregnancy; frequent contact } \\
\text { and control; availability; a holistic perspective; trusting } \\
\text { relationships; } \\
\text { not being judged; a } 360^{\circ} \text { turn; }\end{array}$ \\
\hline $\begin{array}{l}\text { Balancing motherhood and drug } \\
\text { addiction: The transition to parenthood } \\
\text { of addicted mothers (2012) }\end{array}$ & $\begin{array}{l}\text { Silva SA, Pires AP, } \\
\text { Guerreiro C, Cardoso A }\end{array}$ & $\begin{array}{l}24 \text { drug addicted } \\
\text { mothers on methadone } \\
\text { with ages } 25-42 \text { and } \\
\text { children } 1-32 \text { months } \\
\text { of age }\end{array}$ & Grounded Theory & $\begin{array}{l}\text { Semi-Structured } \\
\text { interviews }\end{array}$ & $\begin{array}{l}\text { Circumstances for substance abuse during pregnancy; } \\
\text { Ambivalence between addiction and pregnancy/parenting; } \\
\text { Functional (minimal) parenting; Intervening factors: family } \\
\text { support to parental role }\end{array}$ \\
\hline $\begin{array}{l}\text { Beliefs and behaviors of pregnant } \\
\text { women with addictions awaiting } \\
\text { treatment initiation (2017) }\end{array}$ & $\begin{array}{l}\text { Van Scoyoc A, } \\
\text { Harrison JA, Fisher PA }\end{array}$ & $\begin{array}{l}15 \text { women who were } \\
\text { either pregnant or } \\
\text { postpartum who had } \\
\text { used illicit substances } \\
\text { during pregnancy }\end{array}$ & Grounded Theory & $\begin{array}{l}\text { Semi-Structured } \\
\text { Interviews }\end{array}$ & $\begin{array}{l}\text { 4 Categories: Beliefs about the negative impact on the baby of } \\
\text { substance use during pregnancy; } \\
\text { Seeking information about the impact of substance use; } \\
\text { Reducing substance use prior to accessing treatment services; } \\
\text { Engaging in health promoting behaviors }\end{array}$ \\
\hline $\begin{array}{l}\text { Experience of recovery for female heroin } \\
\text { addicts: An interpretive pheno- } \\
\text { menological analysis (2011) }\end{array}$ & Watson L, Parke A & $\begin{array}{l}5 \text { Female heroin } \\
\text { addicts }\end{array}$ & $\begin{array}{l}\text { Interpretive } \\
\text { phenol- Menolo- } \\
\text { gical analysis }\end{array}$ & $\begin{array}{l}\text { Open ended, semi- } \\
\text { structured } \\
\text { interviews }\end{array}$ & $\begin{array}{l}\text { Super-ordinate themes: Childhood experiences; physiological } \\
\text { and physiological and psychological effects; and perceptions of } \\
\text { recovery }\end{array}$ \\
\hline $\begin{array}{l}\text { Methadone, buprenorphine and } \\
\text { preferences for opioid agonists } \\
\text { treatment: A qualitative analysis } \\
\text { (2016) }\end{array}$ & $\begin{array}{l}\text { Yarborough BJH, } \\
\text { Stumbo SP, McCarty } \\
\text { D, Mertens J, Weisner } \\
\text { C, Green CA }\end{array}$ & $\begin{array}{l}\text { Adults with opioid } \\
\text { dependence (238) }\end{array}$ & $\begin{array}{l}\text { Coded using Atlas. } \\
\text { ti }\end{array}$ & $\begin{array}{l}\text { Interviews, audio- } \\
\text { recorded, trans- } \\
\text { cribed verbatim }\end{array}$ & $\begin{array}{l}\text { Awareness of treatment options; expectations and goals for } \\
\text { duration of treatment and abstinence; prior experience; need for } \\
\text { accountability; preference to avoid methadone clinics; fear of } \\
\text { continued addiction; pain control }\end{array}$ \\
\hline
\end{tabular}


Many women experienced feelings of anxiety, depression, and even had panic attacks. One woman said that her "heart would beat fast, it races like mad, then I get this feeling like I'm in trouble, and I've done nothing wrong. It happens at night, you know, when I'm laid in bed, and I think why I am worrying? (Watson and Parke, 2011)." Women without social support experienced more ambivalence. Even if they were in a drug treatment facility, there was fear of how methadone or Suboxone would affect the pregnancy. One woman stated, I had only been back on the methadone for, like, 3 weeks when I found out that I was pregnant. So mainly I was, like, scared and mad, like I wish I would've known 3 weeks ago (that I was pregnant), because I just wouldn't have gotten back on it, I would have just sucked it up, and, you now, did the detox at home by myself so I wouldn't have to have a baby that has withdrawals (Howard, 2016).

Another woman found out she was pregnant while on methadone, and felt that "at least it was the lesser of two evils (Chandler et al., 2013)." The women feared that what they were doing would affect their infants. They did not want to watch their infants withdraw from what they had put in their bodies. They described shame and guilt for what they put their infants through, but they also voiced a helplessness of being able to stop it (Cleveland and Bonugli, 2014). Although women described being able to make some positive changes, they also described struggling to decrease their use of substances they were dependent upon and often making unsuccessful attempts to quit (Van Scoyoc, 2017)."Fear. Fear, in the end, I'd say, my rock bottom was fear (Watson and Parke, 2011)."

Stigma. Addicted women described feelings of self-judgement, self-hatred, shame, and guilt when talking about their addictions and the effects on their infants. One woman said, "I know it's my fault, but she should't have to suffer because of things I chose to do (Cleveland and Bonugli, 2014)." Another said, "I did bad. I hurt him, you know? If it wasn't for my drug use, my stupidity, he wouldn't be going through this. I put him through this...I put him in that situation (Cleveland and Bonugli, 2014)." The women spoke about being incapable of control, stating that no drug addict would be able to keep from using the drugs, thus relieving them of their responsibility (Silva et al., 2012). Others felt it would be better for them and their pregnancy/infants to remain on a stable dose then to try to wean off the drugs (Chandler et al., 2013). The drugs consumed their lives, and they had little room left for being mothers.

The women felt judged by the providers, doctors and nurses, when the women went to appointments or were in the hospital. Many times the women felt as though the nursing staff negatively judged them because of their history of drug use. "I would be watched whenever I was holding my baby (Cleveland and Gill, 2014)." One NICU nurse called an addicted mother a "junkie mom" (Cleveland and Bonugli, 2014). Another said, "the nurses would be rolling their eyes...It made me feel ugly (Cleveland and Gill, 2013, p. 203)."Some women felt that they deserved judgement because of what they had done to their infants, as long as the nurses treated their infants correctly (Cleveland and Bonugli, 2014).

Trust

The synthesized finding of Trust included two themes: Mistrust and Assurance.

Mistrust. Women with opioid addictions had difficulty with trust. They had experienced the fear, ambivalence, and stigma that described above. They had 
difficulty trusting themselves, and if they could not trust themselves, it was not possible to trust others. They worried that the health providers around them would contact authorities about them-police regarding their addiction, or CPS to come and take the infant. The women did not want anyone to come and take the infant out of the room fearing they may never see the infant again (Watson and Parke, 2011). Many women participated in treatment programs just so they could retain custody of their child/ children. One mother stated that she was replacing her addiction for heroin with an addiction for methadone in order to keep her infant (Chandler et al, 2013).

Assurance. There are programs for addicted pregnant women, or women with young infants that provide support for the women with a holist perspective. The health providers provide a trusting relationship and collaborate with the woman throughout her pregnancy. The women viewed the nurses as caring when they took the time to communicate on a personal level. "She would share her life with me...She knew something about me and I knew something about her (Cleveland and Gill, 2013)." Some programs provide women with counseling regarding parenthood, and addiction. They show respect to the women. One woman stated, "They show respect for what you have experienced, they are understanding (Nordenfors and Höjer, 2017)." Another woman stated, "It was not like, you are a bad person, you have led a bad life and now we have to control you," not at all. They had a positive attitude, which I really appreciated (Nordenfors and Höjer, 2017)."

\section{Educational Deficits}

The synthesized finding of Educational Deficits included two themes: Nurses not truly understanding addictions and little understanding about addictions.

\section{Nurses do not truly understand} addictions. In reviewing the chosen articles, the articles made it clear that there was a pervasive perception of stigma presented to the women. The women did not feel that the nurses understood what the women were experiencing (Howard, 2016). "I felt judged. I felt like the nurses thought of me as a drug user and that was my whole life story (Cleveland and Bonugli, 2014)." This strained relationships between the nurses and the mothers, leaving the mothers feeling judged by the nurses.

Little understanding about addiction. There was understanding about the statistics of opioid dependence in pregnancy, but there was little understanding of how quickly an addiction can occur in a woman" s life and the power it could hold over her life. "It got out of control-fast... you're extremely paranoid when you're on meth.

...you don't think rationally. It's all about you, you, you (Haight et al., 2009)." There is no woman ever who goes out to become addicted on pain relievers, tranquilizers, stimulants and sedatives. The stereotype of the addicted woman in the back alley buying drugs is not an accurate picture. No educational level, social class, or residential location can protect a woman from opioid addiction.

Opioid use in pregnancy is associated with a risk of neonatal abstinence syndrome (NAS) which results in neonatal morbidity, irritability, feeding difficulty, emesis, loose stools, respiratory distress and other difficulties. Many addicted women not only use opioid drugs, but frequently smoke cigarettes, drink alcohol, and marijuana, compounding the substance exposure to the infant (Forray, 2016).

While there is a want for knowledge exhibited by many opioid-addicted pregnant women, the knowledge received is often times unreliable, inaccurate, and 
incomplete. In correlation to the fear of effects identified within the population, most women want knowledge about their addictions. Women often "sought information about the effect of their substance use during pregnancy on the developing infant" and that "women reported reading information in books, talking with friends, talking with parents, and learning about the outcomes associated with prenatal exposure during prenatal appointments (Van Scoyoc, 2017)."

When asked about effects of opioid abuse on the fetus, many mothers referenced peers and the perceived effects drug use had in different situations. In one quoted several different women as saying very similar things regarding their own personal observations regarding drug use on the fetus. One woman stated,

If they've used meth their whole pregnancy, I've heard that and seen actually some babies are born with, you know, their ears could be folded down a little, or their eyes, they could have trouble with their eyes. You know, clubbed foot. I mean I've seen it and I've heard it (Van Scoyoc, 2017).

Another woman stated,

My [friend] did a lot of pills and alcohol and had a baby...he was like six months old and couldn't eat on his own and it was due to drugs and alcohol. He has a feeding tube for the rest of his life and he can't really talk to you (Van Scoyoc, 2017).

Mothers reported seeing and hearing of children with defects attributed to drug use. This speculation aided in the growth of fears, as well as internal stigma, within these mothers (Van Scoyoc, 2017).

In addition to peers, women often reported spending time on the Internet trying to find information about the effect of drug use on their child. One woman said that she spent up to 70 hours on the
Internet researching and would simply read over the same things over again. The women who reported using the Internet for research did "goal driven" research; their goal was to find the impact of drug use on the fetus. One woman in particular stated that she wanted to know if the fetus was high in her body. Other women tried to find facts backing up their drug use, such as opioid use having no specific harmful effects on the fetus (Van Scoyoc, 2017).

\begin{tabular}{l}
\hline DISCUSSION \\
\hline We identified Overarching Fear, Trust, and \\
Educational Deficits as the synthesized \\
findings in this review. Most addicted \\
women suffer from low self-esteem, social \\
isolation, and are vulnerable. They place \\
their health and the health of their infants \\
in the hands of the nurses, and the women \\
are scared (Watson and Parke, 2011)
\end{tabular}
Women come to expect victimization in so many areas. Women, who were addicted to opioids, fear stigma related to feelings of judgment from the nurses and providers who cared for them and their infants. These mothers need emotional support, but support is not always received (Cleveland, 2008). Many of the women interviewed in the various articles discussed how the nurses and providers judge and blame them. The American Nurses Association is very clear in the Code of Ethics for Nurses that nurses should "practice with compassion and respect for the inherent dignity, worth, and unique attributes of every person (Provision 1, ANA Code of Ethics for Nurses, 2015)." This provision encompasses respect for human dignity, establishing a relationship of trust and providing nursing services according to need, and respecting the dignity and rights of all human beings regardless of the factors contributing to the person" s health status, and right to selfdetermination (Provision 1, ANA Code of 
Journal of Maternal and Child Health (2019), 4(6): 461-473

https://doi.org/10.26911/thejmch.2019.04.06.07

Ethics for Nurses, 2015).

Throughout all of the studies reviewed, it was alarmingly clear that many women have a lack of knowledge of the effects of drug use on themselves, their fetus, and how quickly one can fall into addiction. One woman said that "drugs were more powerful than the love for her children...and [then she would use the drug] to get rid of the shame and guilt for what I was feeling...I had low self-esteem...I gave up hope (Haight et al., 2009).” The literature describes the quickness with which the woman becomes obsessed with the drug and how the drug becomes more important than anything else in their lifeeven their children (Haight et al., 2009). They lose their ability to think rationally.

The addicted women in this review were very worried about what they had done to their infants. They felt guilt and self-shame over the effects of their drug use on their infants. This made information regarding their infant all the more important. Some women felt that the NICU personnel excluded them from the care of their infants because of their addiction, or they did not receive accurate or complete information regarding their infant's condition. Approaches that encourage the mothers to participate in their infants' care, treating the mothers with respect, and maintaining an active, informative dialogue added the ability for the mothers to build trust with the nurses (Cleveland, 2008).

The women also wanted to have options within their own addiction treatment, as well as patient education and patient-provider communication. Without these, they had difficulty trusting, felt judged and were vulnerable. Yarborough and colleagues (2016) corroborated these feelings in their article. They found that when there was better collaboration, improved education, and partnership in addiction treatment decisions, the patients were more likely to remain in treatment (Yarborough et al., 2016).

\section{Implications for Providers}

Providers can aide in reducing stigma, building trust and helping educate mothers. Healthcare providers need education to understand women with addictions. Education should include physiological aspects of opioid addiction so that practitioners and nurses know more about withdraw and how to properly detoxify pregnant women.

Without proper knowledge, providers may come across negatively to the mother. Focused sessions about healthcare help to reduce stigma and decrease an addicted women's fears. Educational sessions and online modules highlighting the thoughts and feelings of pregnant women who are addicted to opioids are ways to provide education. Practicing unbiased, active listening sessions help to reduce stigma.

This encourages mothers to speak openly about their addictions and the barriers they are facing. Active listening also promotes trust in the nurses, and other healthcare providers, by making mothers feel heard and cared for. Nurses should also create positive-nurse patient relationships pro- mote trust, as it is a key aspect in the process of reducing stigma. If mothers feel they can trust healthcare providers, they are more likely to reach out for help. Healthcare providers should treat each woman as an individual. As each woman is an individual, each addicted woman is also an individual and will have individual needs.

Education for the addicted woman is a key. By providing outreach without judgement to women who use opioids, health care providers increase the mothers" trust in the healthcare system, making them more likely to reach out for help when they 
become pregnant. This may be a simple patient education that occurs during an exam or in a group setting. This allows women to ask questions and receive feedback. Pamphlets or other written information may also be beneficial in promoting education. Written information allows women to have information to look back on and read when they cannot be with a healthcare provider to ask questions. Education should include the effects of opioids on the fetus, ways to stop opioid use, and how to best manage withdrawal symptoms.

Healthcare providers should know where and how to access treatment centers that provide medications to lessen withdrawal symptoms and provide support groups. Physical and psychological management of withdrawal symptoms make withdrawal seem less daunting and more manageable. Pregnant women need better treatment care for withdrawal as many standard treatments cause harm to the fetus. Better treatment for withdrawal also increases rates at which women try to discontinue drug use, because the withdrawal process seems less daunting and physically demanding. All of these implications should be used together to promote the best results for mothers with opioid addiction.

\section{Limitations}

There is a paucity of research on this topic and the number of women becoming addicted to opioids is growing by astronomical numbers. Many of these women will be in their childbearing years, which increased the likelihood of pregnant women with addictions and the number of infants born addicted.

This review was limited by the inability to find articles that were specific to our topic of understanding the experiences of the addicted mothers during pregnancy and early postpartum and how it relates to nursing.

\section{Potential for Future Study}

Study regarding the differences between opioids and medications used in treatment, such as methadone, suboxone, and others and their effect on pregnancy and postpartum. The women in this review talked about how the drug was stronger than their love for their children, yet, they feared that their children would be taken away. How do we keep women from becoming addicted? How do we get women off opioids during pregnancy and keep them off after delivery so that they can take care of their children? The answer is not just to fix the women. Healthy women come from healthy neighborhoods and communities. The answer comes in fixing the neighborhoods and communities in which they live.

In an editorial reflection by Arrowood (2016), she describes a newly postpartum mother attempting to deal with her infant who is inconsolable due to withdrawing from whatever substances the woman has consumed during pregnancy. Instead of approaching this young woman in a reproachful and judgmental tone, she instead enters the room and offers this new mother several techniques for quieting a hypersensitive child. She shows her how to swaddle the child and rock slowly. With this gentle movement, the baby quiets as the mother whispers her love to the child. It is possible that as this nurse develops a rapport with this new mother, that the nurse may also encourage the woman in her own treatment (Arrowood, 2016).

A meta-synthesis of qualitative study allowed for greater understanding of how pregnant women perceive the consequences of their opioid use. This synthesized review included ten articles that were critically appraised and synthesized following a rigorous methodology. Limitations for this study exist in regard to the low number of qualifying studies. Many mothers who were 
interviewed were interviewed after their pregnancy, so there statements are reflections of the past. Nurses should make an increased effort to help reduce the stigma towards pregnant women with opioid use disorder. Pregnant women can benefit when nurses are informed about opioid use disorder. With increasing rates of opioid use during pregnancy, it is necessary for nurses to know how to care best for patients with opioid use disorder in order to provide the best care for the woman and her baby.

\section{AUTHORS CONTRIBUTION}

Deborah Stiffler, Mia Amundson, Lauren Hapke, Emilie Harvey, Samantha Sizemore, and Savannah Smith collected and selected the articles, proceeded data analysis, and wrote the manuscript.

\section{FUNDING AND SPONSORSHIP}

This study used the authors' independent fund.

\section{CONFLICT OF INTEREST}

None of the authors have any disclosures to declare.

\section{REFERENCE}

Arrowood GL (2016). Inside the eyes of a mother with addiction. Nursing for Women's Health, 20(5): 522-524.

Chandler A, Whittaker A, CunninghamBurley S, Williams N, McGorm K, Mathews G (2013). Substance, structure and stigma: Parents in the UK accounting for opioid substitution therapy during the antenatal and postnatal periods. International Journal of Drug Policy, 24(6): e35-e42.

CDC (2017). Opioid Overview. Retrieved from https://www.cdc.gov-/drugoverdose/data/index.html

Cleveland L (2008). Parenting in the Neo- natal Intensive Care Unit. Journal of Obstetric, Gynecologic \& Neonatal Nursing, 37(6): 666-691.

Cleveland L, Bonugli R (2014). Experiences of Mothers of Infants with Neonatal Abstinence Syndrome in the Neonatal Intensive Care Unit. Journal of Obstetric, Gynecologic \& Neonatal Nursing, 43(3): 318-329.

Cleveland L, Gill S (2013). Try Not to Judge. MCN, the American Journal of Maternal/Child Nursing, 38(4), 200-205.

Forray A (2016). Substance use during pregnancy. F100o Research, 5: 887.

Huang C, Lee I (2008). The first-three years of parenting: Evidence from the Fragile Families and Child WellBeing Study. Children and Youth Services Review, 30(12): 1447-1457.

Haight WL, Carter-Black JD, Sheridan K (2009). Mothers experience of methamphetamine addiction: A casebased analysis of rural, Midwestern women. Children and Youth Services Review, 31: 71-77.

Howard H (2015). Experiences of opioiddependent women in their prenatal and postpartum care: Implications for social workers in health care. Social Work in Health Care, 55(1): 61-85.

Kaiser Family Foundation [KFF] (2018). Medicaid's role in addressing the opioid epidemic. https://www.kff.org/infographic/medicaids-role-in-add - ressing-opioid-epidemic/.

McHugh R, Hearon B, Otto M (2010). Cognitive behavioral therapy for substance use disorders. Psychiatric Clinics of North America, 33(3): 511-525.

National Institute on Drug Abuse [NIDA]. (2014). America's addiction to opioids: Heroin and prescription drug abuse. Retrieved from: https://www- 
.drugabuse.gov/about-nida/legislative-activities/testimony-to-congress/ 2016/americas-addiction-to-opioids -heroin-prescription-drug-abuse.

National Institute on Drug Abuse [NIDA]. (2015). Dramatic increases in maternal opioid use and neonatal abstinence syndrome. Retrieved from https://www.drug-abuse.gov/related-topics/trends-statistics/infographics/dramatic-increases-in-maternal-opioid-use-neonatal-abstinence-syndrome.

Nordenfors M, Höjer I (2017). Mothers with substance and alcohol abusesupport through pregnancy and early infancy. Social Work in Health Care, 56(5): 381-399.

Ross E, Graham D, Money K, Stanwood G (2014). Developmental consequences of fetal exposure to drugs: What we know and what we still must learn. Neuropsychopharmacology, $40(1)$ : 61-87.
Silva S, Pires A, Guerreiro C, Cardoso A (2012). Balancing motherhood and drug addiction: The transition to parenthood of addicted mothers. Journal of Health Psychology, 18(3): 359-367.

Van Scoyoc A, Harrison J, Fisher P (2016). Beliefs and behaviors of pregnant women with addictions awaiting treatment initiation. Child and Adolescent Social Work Journal, 34(1): 65-79.

Watson L, Parke A (2009). Experience of recovery for female heroin addicts: An interpretative phenomenological analysis. International Journal of Mental Health and Addiction, 9(1): 102-117. Yarborough BJH, Stumbo SP, McCarty D, Mertens J, Weisner C, Green CA (2016). Methadone, buprenorphine and preferences for opioid agonist treatment: a Qualitative analysis. Drug and Alcohol Dependence, 160: 112-118. 